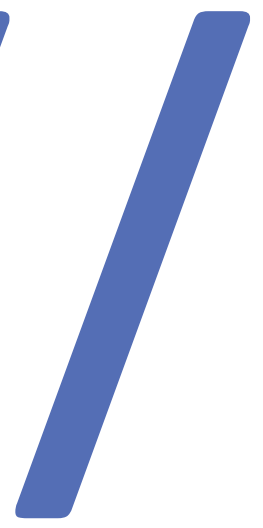

\title{
Testemunha, vivência e as atuações do repórter na TV brasileira*
} Witness, experiences and the actuations of the Brazilian TV reporter

\section{Juliana Freire Gutmann ${ }^{1}$}

\section{Valéria Maria Vilas Bôas ${ }^{2}$}

\section{Itania Maria Mota Gomes ${ }^{3}$}

\footnotetext{
* Este artigo é a versão final de duas comunicações orais apresentadas pelas autoras nos dois primeiros encontros do PIMI (Projet Institutionnel de Cooperátion Scientifique PICS 06714 - Patrimoines-Images-Médias-Identités), em 2015: «Le témoin oculaire de l'histoire' ou celui qui 'vit les faits du dedans au dehors'? La construction du reporter-témoin à la télévision brésilienne ", apresentado no I Seminário do programa PatrimoinesImages-Médias-Identités (PIMI), realizado nos dias 13 e 14 de abril de 2015, em Aix-en-Provence/França; e «Construções de identidade do repórter-testemunha na TV brasileira ", apresentado no II Seminário do programa Patrimoines-Images-Médias-Identités (PIMI), realizado em outubro de 2015, em Salvador.

${ }^{1}$ Professora do Programa de Pós-Graduação em Comunicação e Cultura Contemporâneas da UFBA, Brasil. Doutora em Comunicação e Cultura Contemporâneas pelo PósCom/UFBA, 2012. E-mail: jugutmann@gmail.com

${ }^{2}$ Doutora pelo Programa de Pós-Graduação em Comunicação e Cultura Contemporâneas da UFBA, Brasil. E-mail: lelavbs@gmail.com

${ }^{3}$ Professora do Programa de Pós-Graduação em Comunicação e Cultura Contemporâneas da Universidade Federal da Bahia (UFBA), Brasil. Doutora em Comunicação e Cultura Contemporâneas pelo PósCom/ UFBA, 2000; Bolsista de Produtividade em Pesquisa do CNPQ. E-mail: itaniagomes@gmail.com
} 
Resumo: $\mathrm{O}$ artigo investiga historicidades que constituem o testemunho jornalístico na televisão brasileira, considerando o corpo do repórter como dispositivo de autenticação dos relatos e de constituição de subjetividades. Argumentamos que a noção de testemunha ocular da história, que configura a identidade do repórter desde o Repórter Esso, é uma matriz cultural do telejornalismo brasileiro e evidenciamos reconfigurações dessa matriz, em programas contemporâneos mais especificamente no Jornal Nacional, da Rede Globo, e no programa A Liga, da Rede Bandeirantes, - em torno do repórter que vivencia o acontecimento. Esse processo exibe uma contínua disputa por marcas e convenções que atravessam a história da TV no Brasil e constituem o telejornalismo enquanto uma forma cultural.

Palavras-chave: telejornalismo brasileiro; repórter testemunha; matrizes culturais; gênero televisivo; estrutura de sentimento.

Abstract: The article investigates historicity aspects that constitute journalistic reports on Brazilian television, considering the reporter's body as an authentication device of the accounts and of construction of subjectivities. We argue that the concept of being an eyewitness of history, which forms the news reporter's identity since the start of the Brazilian version of the program Your Esso Reporter, is a cultural matrix of Brazilian television journalism. We also highlight the reconfigurations of this matrix in contemporary television newscasts - more specifically in Jornal Nacional by Rede Globo and in A Liga by Grupo Bandeirantes regarding the news reporter who experiences an event. This process shows a continuing dispute over characteristics and conventions found over the history of television in Brazil and that establish television journalism as a cultural form.

Keywords: Brazilian television journalism; eyewitness reporter; cultural matrices; television genre; structure of feeling. 
“Alô, Alô, quem fala é o Repórter Esso, testemunha ocular da história”. A frase proferida em tom eloquente, nos anos 1940, pelo locutor do radiojornal de maior prestígio no Brasil ${ }^{4}$ talvez seja a principal memória que partilhamos sobre o discurso de autolegitimação do jornalismo no país. Impera, nesta definição, uma dimensão histórica da prática, apropriada para justificar sua deontologia - como nos lembra Ribeiro (1999) - articulada a uma dimensão comunicativa, que a coloca como instância através da qual estaríamos postos em relação com o mundo no momento presente. Esse lugar de interação tem na ideia de testemunha ocular uma espécie de matriz cultural que respondeu, ao longo do tempo, por modos de ser, fazer e perceber as narrativas jornalísticas.

$\mathrm{Na}$ TV, a notícia aparece encarnada em corpos e vozes (de repórteres, apresentadores, comentaristas e fontes), que constituem uma espécie de ecologia de testemunhos, na qual o espectador é inserido, também na condição de testemunha, para legitimar a história narrada ("aconteceu, eu vi na TV"). Tomando o telejornalismo como situação de debate, a questão que nos interessa neste momento não é exatamente compreender o fato a partir dos testemunhos, mas o testemunho como forma de certificação da figura do repórter construído historicamente. De modo mais específico: o testemunho que toma corpo na figura do repórter e que constitui matriz de sua atuação. Nossa apreensão do fenômeno não se dirige exatamente ao que diz esse sujeito que tem voz soberana nas reportagens, mas a sua presença, seu corpo em cena e às relações criadas com os contextos espaço-temporais e seus interlocutores.

Através de seu corpo, do recurso do olho no olho e do fato de se posicionar (ainda que simbolicamente) no local do acontecimento, a figura do repórter se impõe como importante dispositivo de autenticação dos relatos telejornalísticos e de constituição de subjetividades. Sua presença - seja pela voz, pelo corpo ou pelos enquadramentos de câmera - personifica o próprio caráter testemunhal da TV. Neste artigo, buscamos investigar vestígios de uma matriz cultural que aparece como força identitária do repórter desde o Repórter Esso, na década de 1950. Tal matriz orienta a consolidação de uma performance específica, institucionalizando marca de reconhecimento do gênero telejornal ao longo do século XX. Na contemporaneidade, reconfigura-se como dimensão de vivência do acontecimento. O espaço de subjetividade, que transita entre as ideias de "testemunha ocular da história" e de "sujeito implicado no fato narrado", não eclode em um determinado período, mas sim enquanto contínua disputa por marcas de continuidades e descontinuidades que atravessam tempos-espaços e respondem pelo telejornalismo enquanto forma cultural.

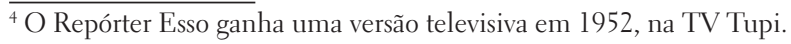


Adotamos aqui a expressão "matriz cultural" no sentido que lhe é atribuído por Jesús Martín-Barbero (2008) em suas várias formulações do mapa das mediações, e retrabalhado por Gomes (2011). Ao pensar a instância das matrizes culturais, Martín-Barbero (2008) construiu o percurso que mostra como a telenovela negocia com a história popular, evidenciando como práticas e formas da cultura popular são configuradores do melodrama e, por consequência, da telenovela na América Latina. Acreditamos que o autor, em razão do contexto midiático da América Latina e do momento histórico em que produziu suas investigações sobre a telenovela, concebe as matrizes culturais do popular como algo anterior aos processos de configuração da cultura massiva - o que estaria em sintonia com a importância política que o debate sobre cultura popular, com suas características de autenticidade e resistência, teve nos anos 1980 entre nós. A concepção de matrizes culturais parece se configurar em Martín-Barbero, então, como matrizes de uma cultura que opera "antes" ou "fora" da cultura midiática, e isso na mesma medida que ele constitui o eixo diacrônico do mapa das mediações como uma relação entre matrizes culturais e formatos industriais que traduziria a relação popular/massivo (nos termos de Martín-Barbero (2008), como matrizes populares se fazem presentes na configuração de produtos massivos). Em nossa perspectiva, temos trabalhado com a hipótese que, diante da consolidação da cultura midiática e da configuração de um entorno tecnocomunicativo (MARTÍN-BARBERO, 2009b), não devemos entender as matrizes culturais como algo pré-midiático ou a-midiático (GOMES et al, 2016; GOMES et al, 2017). No trabalho analítico que desenvolvemos no Centro de Pesquisa em Estudos Culturais e Transformações na Comunicação/TRACC 5 , percebemos que alguns formatos industriais se articulam com matrizes culturais conformadas no próprio campo midiático, que seriam, nesse caso, já matrizes culturais do massivo ou matrizes culturais midiáticas.

Para dar conta dessa investigação, discutimos, a partir da identificação do telejornal Repórter Esso como matriz cultural midiática da convenção que toma o corpo do repórter como lugar de autenticação do relato jornalístico através da noção de testemunha ocular da história, o lugar do testemunho e da vivência do repórter na televisão contemporânea. Neste artigo, o nosso olhar analítico se concentra em dois modos de atualização dessa matriz. Por um lado, a cobertura feita pelo Jornal Nacional (GOMES, 2009) - que foi se consolidando ao longo do tempo como principal referência em relação à forma do telejornal brasileiro - do atentado ao jornal satírico francês

\footnotetext{
${ }^{5}$ Para saber mais sobre o Centro de Pesquisa em Estudos Culturais e Transformações na Comunicação/ TRACC, http://tracc-ufba.com.br.
} 
Charlie Hebdo, em janeiro de 2015, nos ajuda a ilustrar performances contemporâneas que reforçam esse sentido testemunhal e a argumentar em razão de uma transição da convenção de performance do repórter televisivo, que já se faz presente mesmo no lugar de expressão mais hegemônica da linguagem do jornalismo de televisão. Por outro, a análise da performance pela qual atuam repórteres do programa A Liga, da Rede Bandeirantes, nos indica uma estratégia diferente, ao prometer a seus espectadores que sejam eles mesmos testemunhas da vivência que seus repórteres têm na relação com o fato noticiado posto em cena na televisão.

\section{O repórter "testemunha ocular": convenções em transição}

Em uma investigação sobre a palavra "experiência", apresentada no livro Palavras-chave, Raymond Williams (2007), distingue dois usos importantes da palavra a partir do século XVIII: o primeiro se refere à experiência como conjunto de conhecimentos acumulados, portanto referentes a um passado; o segundo como um tipo específico de consciência "que pode em alguns contextos ser distinto de 'razão' ou de "conhecimento" (WILLIAMS, 2007, p. 172). Nesse sentido, Williams destaca que nesse segundo uso está implícita uma distinção entre espécies de consciência e que "para alguns, aparentemente, um pensamento não seria uma experiência, mas um ato (menor) de raciocínio ou opinião" (WILLIAMS, 2007, p. 172, grifos do autor). Assim, o apelo à experiência seria um apelo à totalidade do ser, e não a estados ou faculdades mais limitadas, mais especializadas. Esse apelo à totalidade vai "contra formas de pensamento que excluam certos tipos de consciência como 'pessoais', 'subjetivos' ou 'emocionais”' (WILLIAMS, 2007, p. 173), mas virou um problema quando experiência passou a ser uma palavra usada para designar uma espécie de verdade absoluta no metodismo religioso:

Uma descrição de 1857 registra que 'havia orações e exortações, relatos de experiência, cantos [...], hinos sentimentais'. Eis aí uma noção de testemunho SUBJETIVO oferecido para ser compartilhado. O que é importante, para um sentido posterior mais geral, é que tais experiências são oferecidas não apenas como verdades, mas como a espécie mais autêntica de verdade. (WILLIAMS, 2007, p. 174, grifos do autor)

Essa noção de testemunho como a mais autêntica verdade é certamente presente ainda no modo como a noção de testemunho jornalístico do repórter ajuda a autenticar o seu relato dos fatos. Assim, afirma Bruno Leal (2003, p. 1-2),

[...] o jornalismo se baseia num pacto de credibilidade com seu leitor, a ser posto em xeque e reafirmado na elaboração 
e na recepção de cada uma de suas histórias. Muito dessa credibilidade vem exatamente da apresentação do repórter como testemunha dos fatos. Sua presença no local dos acontecimentos é um dos elementos-chave para a autenticidade e, consequentemente, credibilidade, do relato que produz.

A materialização do corpo do repórter como algo visível para o espectador a partir do surgimento da televisão reafirma esse pacto de credibilidade. No Brasil, a presença da televisão em cena, personificada pelo corpo do locutor e não apenas sua voz, tem o telejornal Repórter Esso como matriz cultural midiática para pensar o lugar do repórter-testemunha no telejornalismo brasileiro. Identificamos um trecho da cobertura ${ }^{6}$ feita pelo Repórter Esso da Copa de 1970, realizada no México. Na reportagem exibida sobre a preparação e expectativa da equipe de futebol brasileira, dois repórteres se posicionam no mesmo cenário, o hotel em que a seleção está concentrada. Os enquadramentos de câmera abertos enfatizam o espaço da piscina, os jogadores em momentos de lazer, fotógrafos e repórteres, entrevistas com atletas. No momento em que um dos repórteres pergunta ao jogador sobre um lance do jogo, ele pede para a câmera dar um close do machucado no rosto do goleiro e diz: “agora mostra aqui para o telespectador... faz um close aproximando, olha aí ô, a pancada no rosto do Félix, naquele lance tão difícil e de importância máxima para a seleção brasileira". A presença do repórter no "local do acontecimento", bem como a demonstração, via imagem, do que se diz, aparecem como estratégias de certificação do testemunho do telejornal. Outro elemento é forte na atuação do mediador: o tom dramático e a relação de intimidade constituída com os espectadores (os repórteres encenam um diálogo com a câmera) e com os entrevistados (que aparecem sem camisa, dentro da piscina, olham para a câmera e chegam a segurar o microfone, tomando o lugar do mediador).

O “seu repórter Esso" (como o programa se autodenominava) personificava um sujeito cuja autoridade para falar sobre as coisas do mundo era construída pelo tom emotivo, eloquente e, por vezes, pessoal - elemento diluído durante a segunda metade do século $\mathrm{XX}$, quando o corpo do repórter se consolida como forma identitária do gênero telejornalismo e os valores do chamado “jornalismo moderno" (objetividade, vigilância, imparcialidade etc.) se institucionalizam. O lugar da "testemunha ocular" tem, a partir daí, na impessoalidade e formalidade atributos centrais de disputa por credibilidade. A "nova” equação prevê que o grau de

$\overline{{ }^{6} \text { Trecho capturado de }}<$ https://bit.ly/2QMyeJK $>$ em 26 mar. 2018. 
confiabilidade dado ao repórter seja proporcional a seu grau de distanciamento do fato narrado, ainda que na condição de testemunha.

Conforme os manuais de telejornalismo das emissoras brasileiras, que institucionalizaram seu ensino e prática ao longo do século XX, nos momentos em que o narrador se torna visível na tela, ele deve se apresentar sobriamente de modo a não fazer sua aparência se sobressair em relação ao que é dito. Ao mesmo tempo em que se projeta no fato, reportando-o in loco, sua atuação corporal deve representar um "sujeito imparcial", mera figurativização do telejornal. É o corpo do "homem civilizado", que se veste de modo sóbrio, tem expressão facial séria e gestos comedidos. As qualidades desse sujeito corporificado são pautadas por uma lógica relacional, na qual o valor positivo estaria relacionado a uma suposta qualidade "neutra", um "não eu” autorizado a falar sobre o fato com objetividade porque aparentemente não envolvido (GUTMANN, 2014).

A especificidade da televisão de demonstrar, a partir de imagem e som, o dito pelo texto verbal reforça a constituição desse lugar de "testemunha ocular", cuja matriz cultural televisiva, como vimos, é reconhecida no Repórter Esso. A partir da análise da cobertura feita pelo Jornal Nacional, telejornal mais antigo em exibição do Brasil, do atentado terrorista ao jornal satírico francês Charlie Hebdo, em janeiro de 2015, ilustramos performances do repórter que reforçam esse sentido testemunhal. $\mathrm{Na}$ video tape (VT) sobre as manifestações de luto na França após o atentado, exibida pelo Jornal Nacional em 8 de janeiro de 20157, no trecho que corresponde à passagem ${ }^{8}$, o desenho visual do quadro proposto pelo repórter cinematográfico - que sai do close no letreiro com o nome da rua Nicolas Appert e se movimenta em direção a um amontoado de flores e velas em homenagem às vítimas do atentando - ilustra, de modo redundante, o texto verbal da repórter: "a rua Nicolas Appert virou um local de peregrinação. As pessoas deixam flores, velas, bilhetes”. A autenticação da reportagem depende desse processo de demonstração via valorização de entrevistas, imagens e áudio ambiente como estratégia de aproximação do tempo-espaço do fato testemunhado pelo repórter (no VT, a ausência de som é reforçada pela suspensão do áudio quando a repórter diz: "silêncio, em respeito às vítimas").

Diferentemente do "seu repórter Esso", quando mostra seu corpo, a repórter, na passagem descrita, olha para o espectador, mas não insinua nenhum tipo de

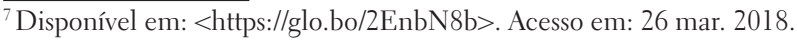

${ }^{8}$ Passagem do repórter: gravação feita pelo repórter na qual sua imagem aparece. A passagem é inserida no meio da reportagem (GUTMANN, 2014, p. 268).
} 
diálogo com ele. Já os entrevistados não "olham” para o público, mas para a repórter, o que reforça a presença da jornalista em cena, salientada pelo enquadramento aberto da câmera em todas as entrevistas. Cria-se uma espécie de camada (moldura) de mediação imprescindível para o jogo comunicativo proposto: só os repórteres estariam autorizados a trazer os testemunhos sobre o fato até nós.

Tem-se como elemento de continuidade aqui, em relação ao Repórter Esso, o credenciamento do dito pela construção do repórter como "testemunha ocular", e não na sua inclusão como personagem da ação narrada. Ao mesmo tempo é claro um marco de descontinuidade quando se oblitera o tom de emotividade presente na interpretação verbal do mediador. É possível notar o esforço, do ponto de vista verbal e audiovisual, em colocar a repórter no lugar daquela que presencia o fato para tornar o relato autêntico. Como forma de validar os atos reportados, o espectador também é convocado a testemunhar, no sentido de ver, atestar, verificar, comprovar, ou mesmo presenciar, aquilo que é dito pela narradora.

Como aponta Leandro Lage (2015), pesquisas recentes sobre a televisão brasileira têm percebido transições de ordens retórica, discursiva e performática nesse tipo de construção do "repórter testemunha" (FECHINI, 2008; GUTMANN, 2014; EVANGELISTA, 2015; VILAS BÔAS, 2018). Sua atuação se torna mais flexível e ele passa a ocupar efetivamente as cenas dos acontecimentos enquanto "ator" e não apenas "aquele que reporta". Um aspecto que já era da ordem do arcaico ${ }^{9}$ - o tom de intimidade e a dramaticidade das personificações do Repórter Esso - reaparece e se reconfigura na contemporaneidade. Há agora a assumida configuração de uma persona: o jornalista que interpreta representações do cidadão, o sujeito social que se implica nos relatos e faz de seu corpo lugar de personificação da notícia (GUTMANN, 2014). Nesse segundo movimento, o consagrado "padrão de conduta" - quando o repórter atesta sua presença no local do acontecimento a partir de um "não eu" - é borrado pela assumida configuração de um "eu" que utiliza seu corpo (expressões

\footnotetext{
${ }^{9}$ Jesús Martín-Barbero (1995) recupera de Raymond Williams a consideração que a heterogeneidade de temporalidades sociais vividas em cada sociedade, num determinado momento histórico, deve ter em qualquer análise da cultura. As noções centrais para Williams $(1979 ; 2008)$ são as de residual, arcaico, dominante, novo e emergente. Williams se refere aos elementos arcaicos para marcar a distinção com o que ele compreende como elementos residuais. Arcaico é "aquilo que é totalmente reconhecido como um elemento do passado, a ser observado, examinado, ou mesmo, ocasionalmente, a ser 'revivido' de maneira consciente, de uma forma deliberadamente especializante. O que entendo pelo 'residual' é muito diferente. O residual, por definição, foi efetivamente formado no passado, mas ainda está ativo no processo cultural, não só como elemento do passado, mas como um elemento efetivo do presente" (WILLIAMS, 1979, p. 125). Para Martín-Barbero (1995, p. 44), a consideração da heterogeneidade de temporalidades significa "uma nova maneira de introduzir a dimensão histórica nos processos de comunicação", o que ele faz ao pensar na mediação da relação histórica das matrizes culturais com os formatos industriais.
} 
faciais, gestualidades, proximidades e distanciamentos da tela, entonações variadas de voz etc.) como dispositivo expressivo de interpretação do dito.

Na cobertura do atentado ao Charlie Hebdo em 2015 realizada pelo Jornal Nacional, podemos observar este outro modelo de performatização do lugar do testemunho. Em reportagem exibida em 13 de janeiro de $2015^{10}$ sobre medidas de segurança adotadas pelo governo francês após o ataque, o repórter faz da situação por ele vivida durante a cobertura a "notícia". Ao dizer em off, no texto verbal: "Jornalistas do mundo todo fizeram fila para entrevistar os colegas que sobreviveram aos ataques. Só era possível entrar no prédio depois de uma revista", revela seu corpo vivenciando a situação narrada (sendo revistado pela polícia na porta do jornal). Na passagem, movimenta-se, fala de modo ofegante e mostra-se em meio à ação reportada: enquanto fala, ensaia uma tentativa de furar o bloqueio feito pela polícia na porta da sede do jornal Liberation, que "cedeu algumas salas para os sobreviventes do Charlie Hebdo", e trava um diálogo inesperado com um dos seguranças do local, que o impede de entrar. Ao atuar como ator-protagonista da cena, convoca o espectador a acompanhar/testemunhar sua suposta tentativa de furar o bloqueio da polícia e entrar no jornal. Ele diz aquilo que demonstra com seu corpo em cena: "a gente não pode passar aqui porque há muitos seguranças". A câmera, em plano sequência, acompanha sua tentativa de falar com um dos homens armados "un minute s'ilvousplaît". Quando barrado, ele se volta para a câmera e diz "ô, não pode passar daqui para lá, segurança total".

Para que haja reconhecimento por parte do espectador, este é convocado a uma posição de partilha - consentimento, cooperação, conivência de adesão tácita ao que vive o repórter no ato de sua enunciação -, sendo alçado ao espaço-tempo do acontecimento pela identificação com essa persona. O sentido de interação através do engajamento do interlocutor com a ação interpretada pelo mediador conforma um mesmo aqui e agora para os sujeitos comunicativos. Vivenciamos a ação, com o repórter, no instante suposto do seu desenvolvimento.

Ao garantir que a posição de sujeito-testemunha se mantenha e, com ela, a demonstração, pelos recursos de imagens, áudio, texto verbal, do que é narrado pelo repórter, evidencia-se o cuidado em não perder o vínculo historicamente construído com o telespectador, reforçando uma das mais consolidadas marcas que caracterizam o telejornal enquanto gênero televisivo. Ao mesmo tempo, ao adotar uma outra performance possível para o repórter, a de persona, o programa explora uma nova

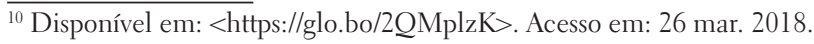


convenção que se configura como estratégia de construção/reconstrução permanente de sua cumplicidade com os telespectadores.

\section{Performances de vivência: novas convenções?}

O repórter que constitui seu corpo como parte do fato narrado coloca-se como sujeito implicado na história contada e é aqui compreendido como sintoma do protagonismo que as "performances da vivência" têm ganhado na TV brasileira e mundial. Em seu livro The power of news (2003), Michael Schudson destaca a importância de reconhecer as formas televisivas enquanto convenções específicas em certas sociedades, chamando a atenção para a relação entre o vivido e a convenção narrativa que tenta relatá-lo. Assim:

notícias em um jornal ou na televisão têm uma relação com o 'mundo real', não só em conteúdo, mas em forma; [...]. Geralmente, as pessoas não veem as notícias como elas acontecem, ao contrário elas ouvem sobre elas. Pais não vivenciam o dia dos filhos na escola diretamente, mas tomam conhecimento deles na medida em que são narrados, tornados histórias pelas crianças ${ }^{11}$. (SCHUDSON, 2003, p. 54, tradução nossa)

A relação entre viver e tornar o vivido história versa, especificamente, sobre o modo como significamos nossas vivências, podendo transformá-las em experiências, ou seja, em algo que pode ser partilhado, que tenha significado para outros além do indivíduo que vivencia a ação. Julio Pinto, numa reelaboração da concepção de Dewey, entende o conceito de vivência como algo relativo a um presente imediato de quem está implicado na situação. Assim, concordamos com o autor para quem "a experiência é uma espécie de memória teórica das vivências. A vivência é o momentâneo, o acidente, o imediatamente sentido” (PINTO, 2010, p. 10)

Ao menos na programação televisiva ocidental, a ideia de um jornalista personagem que corporifica a vivência dos fatos tem se tornado lugar comum. Podemos citar: o programa 30 days $^{12}$, apresentado por Morgan Spurlock, produzido e exibido

\footnotetext{
"No original: News in a newspaper or on television has a relationship to the "real world", not only in content but in form [...]. Generally speaking, people do not see news as it happens, rather, they heard about it. Parents do not experience their child's day at school directly, but learn of it as it is narrated, turned into a story by the child.

1230 Days foi ao ar originalmente no canal estadunidense FX Networks entre junho de 2005 e julho de 2008. Foi ainda exibida em canais do Reino Unido, Austrália, Canadá, Noruega, Suíça e no FX América Latina. Alguns episódios da série podem ser vistos no YouTube ou no Vimeo, a exemplo do primeiro episódio da segunda temporada, disponível neste link: <https://bit.ly/2j8f0ed3>. Acesso em: 29 mar. 2018
} 
pelo canal FX, que propõe 30 dias de imersão em um determinado estilo de vida não familiar ao apresentador para discussão de questões sociais; o Inside $\mathrm{Man}^{13}$, da CNN, em que o mesmo Morgan Spurlock promete uma submersão de si próprio em temas da atualidade; o 21 días $^{14}$, um programa do Canal Cuatro espanhol que coloca sua apresentadora por 21 dias, 24 horas por dia, na pele de distintos grupos de pessoas para compreender e mostrar como são suas vidas; e o Danstesyeux ${ }^{15}$, produzida pelo Arte, companhia de TV franco-germânica, em que Sophie Massieu, uma repórter cega, promete uma viagem inédita de sensações e encontros inusitados pelo mundo. No Brasil, temos o Profissão Repórter, da Rede Globo, que prioriza, em sua narrativa, o discurso sobre si mesmo, fazendo do processo de apuração (o making off) o enredo da reportagem; e o A Liga, da TV Bandeirantes, que tem como marca a suposta imersão dos seus repórteres no cotidiano de seus entrevistados. Cada um a seu modo, o que esses programas prometem aos seus espectadores é que, em vez de confiarem no testemunho dado por seus mediadores, sejam eles mesmos testemunhas da vivência que esses sujeitos têm na relação com o fato noticiado, posta em cena na televisão.

No campo da comunicação, o fenômeno também tem sido alvo de interesse de pesquisadores. Em bibliografia recuperada a partir do Portal de Periódicos da Capes em pesquisas com os termos "journalism + witness"; "journalism + objectivity"; "journalism + subjectivivity"; "journalism + experience"; "journalism + immersive"; e "journalism as experience", novos termos, como jornalismo imersivo (DE LA PEÑA et al., 2010; VAN DE HAAK et al., 2012), jornalismo de ponto de vista (MERTES, 2001; VAN DE HAAK et al., 2012) e mesmo uma argumentação pelo ressurgimento do jornalismo literário a partir de mídias diversas (JACOBSON et al., 2015) aparecem para dar conta de uma série de relações entre o produto jornalístico e seus consumidores a partir de perspectivas que ora propõem uma experiência de imersão na notícia através de uso de ambientes virtuais (DE LA PEÑA et al., 2010;

\footnotetext{
${ }^{13}$ O programa teve 4 temporadas entre junho de 2013 e agosto de 2016, exibidas pela CNN estadunidense. Para ver episódios e maiores informações, o site do programa se encontra neste link: <https://cnn. it/2B9lTW2>. Acesso em: 29 mar. 2018

${ }^{14} \mathrm{O}$ programa do Canal Cuatro teve sete temporadas, exibidas entre janeiro de 2009 e 26 de julho de 2016, e uma versão chilena de uma temporada na Televisión Nacional de Chile. Ao todo, teve três apresentadoras: Samantha Villar (2009 e 2010), Adela Úcar (2011 a 2014) e Meritxell Martorell (2016). Para assistir alguns episódios e consultar outras informações, o site do programa está disponível neste link: $<$ https://bit.ly/2UyJgl8>. Acesso em: 29 mar. 2018.

${ }^{15}$ A série teve 80 episódios em duas temporadas, exibidas em 2012 e 2013. Alguns episódios estão no YouTube. Aquele em que a jornalista visita Katmandu, por exemplo, pode ser visto neste link: $<$ https://bit. ly/2L7zkdT > Acesso em: 29 mar. 2018. A lista de episódios do programa está no IMDB: <https://imdb. to/2QjZlxA $>$. Acesso em: 29 mar. 2018.
} 
VAN DE HAAK et al., 2012; BLAAGAARD, 2013), ora acentuam o caráter pessoal da presença do repórter na feitura do produto noticioso, fazendo vir à tona dimensões de subjetividade (MERTES, 2001; VAN DE HAAK et al., 2012).

Em boa parte desses casos, a relação com tecnologia é destacada na possibilidade de oferta de novas conexões entre o produto jornalístico e seu público, como o uso de mapas em 360 graus para exploração de territórios atingidos por terremotos ou de um olho biônico com câmera para gravação de documentários a partir de uma perspectiva audiovisual em primeira pessoa, que ultrapassa o que se conhece como câmera subjetiva na televisão e no cinema e se aproxima das possibilidades de imersão dos avatares de jogos digitais. Ainda nessa perspectiva, o desenvolvimento de tecnologias de gravação audiovisual cada vez menores e para usos que vão desde a produção de vídeos de família caseiros e funções de vigilância a drones com possibilidade de serem acoplados a câmeras profissionais de cinema para realização de imagens aéreas também tem mudado o cenário da produção televisiva.

Nos programas televisivos ganha relevo a convocação da experiência enquanto partilha do pessoal confesso no relato jornalístico do repórter e do seu fazer, mas também a convocação de sentidos de reconhecimento do jornalismo enquanto uma instituição social. O relato posiciona, então, o repórter como alguém que, além de cumprir uma função testemunhal, partilha, assumidamente, um relato sobre o que afeta a si enquanto sujeito. A tendência configura estratégia de comunicabilidade de programas jornalísticos contemporâneos. Tomaremos a produção brasileira A Liga, do canal de televisão Band como exemplo.

Em sua estreia, em 2010, o programa constituiu sua promessa com a seguinte afirmação: "nós vamos viver a notícia de dentro para fora"16, reiterada nas chamadas da programação. Ao afirmar a vivência pessoal como valor, o programa promete contar aos seus espectadores histórias sobre o mundo a partir de um ponto de vista específico, o do jornalista que vive o fato e que é, antes de apenas testemunha, personagem de sua própria narrativa. Dessa forma, constrói um modo de autenticação da informação em um jogo entre constituições de subjetividades e convocações de valores do jornalismo moderno.

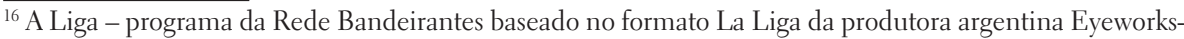
CuatroCabezas - começou a ser exibido no Brasil em 2010 com a promessa de "quanto mais olhos podem ver, mais podem enxergar". Até 2016, teve sete temporadas exibidas no mesmo canal com algumas trocas de apresentadores. O vídeo da chamada para a estreia do programa exibido pela Bandeirantes em 2010 pode ser visto no YouTube em: <https://bit.ly/2UxNdq4>. Acesso em: 10 dez. 2018. No site do programa, é possível ainda ver alguns vídeos de episódios: <https://bit.ly/29OHUws>. Acesso em: 29 mar. 2018
} 
Embora caracterize o lugar de seus mediadores de modo distinto dos telejornais (no A Liga, muitos deles têm suas trajetórias ligadas à indústria do entretenimento), eles são qualificados como repórteres no site da atração e no interior do próprio texto (os mediadores falam de seu trabalho "de repórter" ou "da sua reportagem"). Chamados pelos apelidos - Cazé, Thaíde, Mari e Mel -, eles não usam microfone aparente e vestem-se de modo bastante informal. A atuação desses performers se alia ao extensivo uso da câmera na mão, do plano sequência e de uma edição que privilegia a montagem paralela - tecnicidades ${ }^{17}$ que evocam efeito de autenticidade para a ação vivida.

Na edição do A Liga de 8 de abril de $2014^{18}$, o repórter Cazé vivencia o trabalho de agentes de internação involuntária. Ele acompanha a ação dos agentes, que saem com a mãe de um suposto usuário de crack à procura dele pelas ruas de São Paulo e o encontram em um hotel, no centro da cidade. Na longa reportagem (de 28 minutos e 11 segundos de duração), Cazé está ali como repórter e também como sujeito-cidadão, que testemunha a cena e reage a ela. Seu lugar não é apenas de "testemunha ocular da história": ele atua pela perspectiva dos "sujeitos da lei" (no discurso e na movimentação corporal). De dentro de uma van, ele, os agentes e a mãe do suposto usuário passam por ruas do centro da cidade, abordando pessoas até descobrir que o procurado se encontra em um hotel ali perto.

Já no quarto do hotel, enquanto os agentes tentam conter o suposto usuário, ao perceber uma janela aberta no fundo da cena, Cazé sai na sua direção para fechá-la, como se se desse conta de que o rapaz poderia fugir por ali. Ao mesmo tempo, a interação construída é muito mais forte com a câmera e, portanto, com o telespectador, do que com os sujeitos envolvidos no fato. A certa altura, olha para a câmera e desabafa: "Nossa, eu não consigo nem descrever o que eu tô sentindo, nunca vivi uma situação como essa". Enquanto fala, movimenta-se lentamente, aparenta certo desequilíbrio, dá um passo para trás. Mostra sua mão para a câmera e diz estar tremendo.

Desde o início da reportagem o lugar assumido pelo mediador é um entrelugar - é ele quem dá a ver ao telespectador a cena que se desenrola a partir do que acontece consigo mesmo, mas é ele também que incorpora um lugar de autoridade, distanciado daqueles diretamente envolvidos no acontecimento. Assim, logo no início

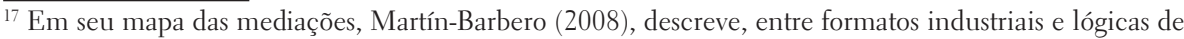
produção, uma mediação da tecnicidade e não da tecnologia. Para o autor, a mudança do nome salienta que confundir comunicação com os meios é tão deformador quanto acreditar que eles são meros acessórios. A tecnicidade envolveria estrutura empresarial, competência comunicativa e competitividade tecnológica, que se expressam através de operadores perceptivos.
}

${ }^{18}$ Disponível em: <http://bit.ly/2H1HMgy>. Acesso em: 26 mar. 2018. 
do VT, Cazé protagoniza uma cena em que as perguntas que faz às fontes oficiais presentes são encenadas a partir de seu próprio corpo e ele é, então, amarrado pelos agentes de internação simulando a abordagem feita com os pacientes nas ruas. Após a encenação, relata o que aconteceu: "Poxa, horrível, cara, a sensação é a pior possível [...]; e eu tô aqui gravando a matéria, sou o repórter, tô entendendo, imagina você tá loucão, assim, você é um viciado, um cara que tá usando crack, brother".

Cazé não usa microfone ou marca de identificação da emissora e é ele mesmo quem pede, no ar, para que a situação que poderá acontecer na ação que ele acompanha - caso encontrem o garoto cuja internação foi solicitada pela mãe - seja simulada consigo. A intenção de colocar-se no lugar do personagem que eles vão acompanhar antes mesmo da situação sugere que é preciso estar nela para conhecê-la de fato. A solicitação, contudo, é construída como um pedido de informação sobre o trabalho dos agentes: "Você imobiliza o quê, os braços pra trás? Como é que é? Vamos supor que eu sou tipo... que eu sou o usuário que vocês tão procurando. Como é que é feita a abordagem?". Os enquadramentos de câmera durante a encenação focalizam as mãos dos agentes, o uso da força para conter Cazé e as tentativas de reação do repórter, com pausas em cada quadro, valorizando a aproximação entre repórter e fontes e a própria encenação. Mas, embora tenha apresentado um relato que tenta dar conta da sensação experimentada, o apresentador estava consciente de si mesmo e, por isso, não reage violentamente ou tenta de fato fugir da situação, que sabe ser passageira e simulada. Quando segue para conhecer a mãe do usuário, que solicitou a internação, contudo, Cazé assume, novamente, uma posição de distanciamento da situação, assumindo o lugar de repórter.

De volta à van, quando o suposto usuário já está detido e questiona a internação, é esse papel de repórter que se destaca e Cazé se dirige ao agente: "em uma situação dessas, em que o paciente se sente sequestrado, como vocês fazem?”. Ainda que o rapaz detido continue questionando quem é o responsável legal por ele naquele momento, o repórter ignora sua reação. A partir daí duas cenas se configuram: no fundo da van, mãe e agentes tentam conversar e conter o rapaz, e Cazé, em primeiro plano, olhando em direção à câmera, explica ao telespectador que o interno está nervoso. Sempre que o choro da mãe, os gestos de força dos agentes - especialmente as mãos que contêm o interno - e a movimentação incessante do garoto ganham o quadro, perde-se Cazé de vista - ele não faz parte daquele momento, está fora da cena. Sempre que volta ao quadro, o repórter constrói, novamente, uma distância com o acontecimento para entrevistar o responsável pela operação. As fontes oficiais, aqui, têm lugar de destaque e legitimidade no discurso. 
Assim, mesmo no centro da cena, misturado aos outros personagens, o mediador de A Liga constrói um distanciamento que marca seu lugar de autoridade, sua possibilidade de afirmar-se repórter. O corpo que vive o acontecimento como forma de testemunhá-lo também recorre a marcas codificadas do jornalismo televisivo. Sim, os corpos postos em frente às câmeras desafiam regras postas em jogo, mas também sustentam um texto e uma construção de apuração, de relação com as fontes, de enquadramentos e edições que valorizam o lugar autorizado do repórter e de seu testemunho sobre o que "vive".

Observa-se um outro modo de performatizar a notícia, que comunga traços da vivência e do testemunho, mas que não se define por mera ruptura com um padrão anterior de postura do mediador frente aos fatos. Esses modos de performatização da figura repórter historicamente construídos não nos parecem distintos ou opostos e muito menos episódicos; ao contrário, são formas culturais que respondem, em diferentes gradações, pela formação desse corpo legitimador dos fatos sobre o mundo desde os primórdios do telejornalismo brasileiro.

\section{Considerações finais}

Esta investigação de caráter analítico evidenciou que disputas por legitimidade, autoridade e credibilidade do jornalismo relacionam-se ao lugar do testemunho construído nos e pelos programas. O testemunho que tem o corpo do repórter como principal figurativização. As formas desses corpos, que se traduzem em convenções, nunca são casuais, fruto de meras escolhas técnicas e normativas, mas são essencialmente relacionadas a transformações na sociedade e aos modos como percebemos, socialmente, essas transformações e articulações.

É interessante perceber como, nos programas mais padronizados, como o Jornal Nacional, o lugar da vivência, atualmente, vem sendo evocado como espaço de legitimação do testemunho, ao passo que os programas que tem a ideia de vivência do fato como estratégia central de endereçamento ainda se valem de marcações/ convenções do gênero como forma de constituição de autenticidade, caso de A Liga. Isso porque, como dito, estamos falando de um processo cultural que não se restringe a uma época ou a um programa, mas que se constitui enquanto permanente processo de disputa entre continuidades e rupturas, naturalizações e desnaturalizações no processo histórico de conformação do próprio jornalismo televisivo.

$\mathrm{Na}$ medida mesmo em que são estratégias de articulação entre valores jornalísticos e linguagem televisiva, os modos de constituição do repórter testemunha evidenciam como os programas se equilibram entre padronização e inovação em 
um esforço constante de se comunicar com o espectador para manter-se na grade de programação. Para Raymond Williams (2001, p. 33), uma convenção é sempre um método criado para dar expressão a um novo modo de sentir. Acreditamos que elas são uma forma de acessar uma estrutura de sentimento e, assim, a emergência de novas características que irão disputar o consenso que temos em torno de procedimentos, normas, formatos, gêneros. Avaliar como novas convenções surgem e como disputam o consenso tácito demanda estarmos atentos a processos de persistência, ajustamento, assimilação inconsciente, resistência ativa e esforço alternativo que caracterizam qualquer processo de disputa por reconhecimento no campo cultural. Demanda, também, um olhar que constitua como "objeto" o espaço de articulação entre textos, entre estes e seus contextos e suas lógicas de produção e de recepção.

Os distintos e, por vezes, contraditórios modos de convocar legitimação social pela atuação do repórter-testemunha, identificados neste artigo, potencializam a compreensão das práticas e instituições a partir de suas relações com a cultura e as transformações sociais. Nos mostram como a televisão brasileira participa de um contínuo processo de mudança cultural que se deixa perceber pela dinâmica entre reiterar convenções que tornam, por exemplo, o telejornal um produto tão reconhecido na grade de oferta televisiva e, assim, reforça marcas de gênero, e adota novos modos de usos dessas convenções e mesmo testa novas possibilidades, estabelecendo novas convenções e novas tendências, inclusive a partir de ressignificações de elementos considerados “arcaicos”. Nessa perspectiva, parece central para nós a compreensão do testemunho em uma perspectiva comunicativa e cultural que nos faz ver, ao longo do tempo, modos de certificação do relato (neste caso, pela constituição do repórter-testemunha) em permanente transformação.

\section{Referências}

BLAAGAARD, B. B. "Shifting boundaries: objectivity, citizen journalism and tomorrow's journalists”. Journalism, Newbury Park, v. 14, n. 8, p. 1076-1090, 2013. Disponível em: <https://bit.ly/2G8ci7L>. Acesso em: 29 mar. 2018.

DE LA PEÑA, N. et al. "Immersive journalism: immersive virtual reality for the firstperson experience of news”. Presence, Cambridge, v. 19, n. 4, p. 291-301, Aug. 2010. Disponível em: <https://bit.ly/2G7bVKP>. Acesso em: 29 mar. 2018.

EVANGELISTA. A. F. “Corporalidade dos apresentadores Como sujeito da notícia na sociedade 'dos meios' e 'em vias de midiatização': cobertura dos movimentos sociais ‘direta já’ e ‘passe livre’ pelo Jornal Nacional”. 2015. 139 f. Dissertação (Mestrado em Jornalismo). Universidade Federal da Paraíba, João Pessoa, 2015. Disponível em: $<$ https://bit.ly/2QG4dLP>. Acesso em: 10 dez. 2018. 
FECHINE, Y. "Performance dos apresentadores dos telejornais: a construção do éthos". Revista Famecos: mídia, cultura e tecnologia, Porto Alegre, v. 15, n. 36, 2008. Disponível em < https://bit.ly/2Qncjts>. Acesso em: 29 mar. 2018.

GOMES, I. M. M. "Les quarante ans du Jornal Nacional, de la Rede Globo de télévision”. Le Temps des Médias, v. 13, p. 56-72, 2009. Disponível em: <http://bit. ly/2RtekUl>. Acesso em: 29 mar. 2018.

. "Gênero televisivo como categoria cultural: um lugar no centro do mapa das mediações de Jesús Martín-Barbero". Revista Famecos: mídia, cultura e tecnologia, Porto Alegre, v. 18, n. 1, p. 111-130, 2011. Disponível em <https://bit.ly/2EkXvVP>. Acesso em: 29 mar. 2018.

. "Qual é a relação entre história e história televisiva?". In: SEMINÁRIO INTERNACIONAL ESTUDOS DE TELEVISÃO BRASIL-FRANÇA. Salvador: Universidade Federal da Bahia, jun. 2013.

et al. "Porque o jornalismo faz rir: matrizes midiáticas do programa Sensacionalista, do Multishow”. In: LISBOA FILHO, F.; BAPTISTA, M. M. (Orgs.). Estudos culturais e interfaces: objetos, metodologias e desenhos de investigação. Aveiro: Universidade de Aveiro; Santa Maria: UFSM, 2016. p. 219-236. Disponível em: http://bit.ly/2AqGSUY. Acesso em: 23 mar. 2018.

.; SANTOS, T. E. F. dos; ARAÚJO, C. S. G.; MOTA JÚNIOR, E. A. "Temporalidades múltiplas: análise cultural dos videoclipes e da performance de Figueroas a partir dos mapas das mediações e das mutações culturais", Revista Contracampo, Niterói, v. 36, n. 3, 2017. Disponível em: <http://bit.ly/2Vt2loZ>. Acesso em: 29 mar. 2018.

GUTMANN, J. F. Formas do telejornal: linguagem televisiva, jornalismo e mediações culturais. Salvador: Edufba, 2014.

JACOBSON, S. et al. "The digital animation of literary journalism". In: Journalism, Newbury Park, v. 17, n. 4, p. 527-546, Feb. 2015. Disponível em: <https://bit. ly/2rtNTiM>. Acesso em: 29 mar. 2018.

LAGE, L. R. "O testemunho na TV: 'Profissão Repórter' e a encenação da encenação". Intercom - Revista Brasileira de Ciências da Comunicação, São Paulo, v. 38, n. 2, p. 139-158, 2015. Disponível em: <https://bit.ly/2zQOaRq>. Acesso em: 29 mar. 2018.

LEAL, B. S. "Do testemunho à leitura: reflexões sobre o narrador jornalístico, hoje". Biblioteca on-line de ciência da comunicação, Covilhã, p. 1-5, 2003. Disponível em: $<$ https://bit.ly/2Em2LZb>. Acesso em: 29 mar. 2018.

MARTÍN-BARBERO, J. "América Latina e os anos recentes: o estudo da recepção em comunicação social”. In: SOUSA, M. W. (Org.). Sujeito, o lado oculto do receptor. São Paulo: Brasiliense, 1995. p. 39-68. 
Dos meios às mediações: comunicação, cultura e hegemonia. Rio de Janeiro: Editora UFRJ, 2008.

“Jesús Martín-Barbero: as formas mestiças da mídia. Entrevista à revista Fapesp”. Revista Fapesp, São Paulo, n. 163, set. 2009a. Disponível em: <https://bit. ly/2qp8dAX>. Acesso em: 23 mar. 2018.

. "Uma aventura epistemológica. Entrevista a Maria Immacolata Vassallo Lopes”, MATRIZes, São Paulo, v. 2, n. 2, p. 143-162, 2009b. Disponível em: <https:// bit.ly/2rsgTYa>. Acesso em: 29 mar. 2018.

MERTES, C. "Where journalism and television documentary meet. NiemanReports, Cambridge, v. 55, p. 53-54. Disponível em: <https://bit.ly/2PtZyHS>. Acesso em: 23 mar. 2018.

PINTO, J. "Logos sensorial: tempo e sensação na contemporaneidade". Contemporânea -Revista de Comunicação e Cultura, Salvador, v. 8, n. 2, p. 1-11, 2010. Disponível em: <https://bit.ly/2QLAGAm>. Acesso em: 29 mar. 2018;

RIBEIRO, A. P. G. "Jornalismo e história: ambiguidades e aparentes paradoxos" Revista Eco-Pós, Rio de Janeiro, v. 4, n. 1, p. 5-10, 1999.

SCHUDSON, M. The power of news. 6. ed. Cambridge: Harvard University Press, 2003.

VAN DER HAAK, B.; PARKS, M.; CASTELLS, M. “The future of journalism: networked journalism”. International Journal of Communication, Los Angeles, v. 6, p. 2923-2938, 2012. Disponível em: <https://bit.ly/2rrczsk>. Acesso em: 29 mar. 2018.

VILAS BÔAS, V. M. Contar não é o mesmo que viver: jornalismo e subjetividade na atuação do repórter na televisão brasileira. 343 f. 2018. Tese (Doutorado em Comunicação e Cultura Contemporâneas) - Universidade Federal da Bahia, Salvador, 2018. Orientadora: Itania Maria Mota Gomes

WILLIAMS, R. Cultura. Trad. Lólio Lourenço de Oliveira. 3. ed. São Paulo: Paz e Terra, 2008.

. "Film and the Dramatic Tradition". In: HIGGINS, J. (Ed.). The Raymond Williams reader, Oxford: Blackwell, 2001. p. 25-41.

. Marxismo e Literatura. Trad. Waltensir Dutra. Rio de Janeiro: Zahar, 1979.

submetido em: 06 mai. 2018 | aprovado em: 23 out. 2018 